\title{
Wall Shear Stress of Blood Flow in Stenosis Artery, Develop Model
}

\author{
Musad Mohammed Musad Saleh \\ Dpartment of Mathematics University of Pune \\ Pune-411007, Maharashtra, India \\ E-mail: almusaediy@yahoo.com \\ Mear Yaseen Ali Khan \\ Department of Mathematics Poona Collage of Arts, Sciences \& Commerce \\ Pune-1, India \\ E-mail: khanmyak@yahoo.com
}

\begin{abstract}
In this paper the mathematical model has been developed to evaluate wall shear stress in the stenosis of artery. The artery is modeled as symmetric stenosis vessel; also the flow of blood is modeled as an incompressible Newtonian fluid. The results show that shear stress have direct proportional relation with both length and height of stenosis. This mathematical model is a useful and a simple toll to evaluate wall shear stress of patients with stenosis artery disease.
\end{abstract}

Keywords: Wall shear stress, Symmetric stenosis artery, Newtonian fluid, Blood flow

\section{Introduction}

Many mathematical and experimental models are used to study hemodynamic of blood, specially the wall shear stress; almost studies show that wall shear stress appears to be closely related to the development of arteriosclerosis (Gringioni and Pontrelli, 2002)

Arteriosclerosis is a common disease which severely influences human health. Early arteriosclerosis lesions are not randomly distributed throughout the arterial tree, they usually tend to form and grow at creation locations, such as the distal to abdominal aorta, coronary and carotid bifurcations (Guo-Tau, et al. 2004).

The wall shear stress distribution is an important diagnostic factor for examining the flow characteristics of the blood through the arteries. Shear stress evolution in stenosis vessel correlated with the complex rheology of the blood explains the decrease of the vessel circular area in time, wall shear stress play an important role in remodeling the arterial wall and can lead to arterial thickening (Mofrad et al. 2005).

Low or oscillating wall shear stress regarded as risk factor in the development of atherosclerotic lesion in healthy arteries and has been fund to be positively correlated to localized intimal thickening of the arterial wall (Nerem, 1992). Shear stress, velocity and pressure are important hemodynamic of blood flow, the presence of unusual hemodynamic condition in the arteries often create abnormal biological responses. The skewing of the blood speed can cause oscillating direction of wall shear stress which can create pockets leading to atherosclerosis disease. In the artery with high stenosis, very high wall shear stress can activate the platelets which can cause thrombosis and may totally block, the pressure is very quickly near the stenosis when the flow reaches the stenosis site then pressure suddenly drops casing a suddenly increases blood velocity (Chan et al. 2007).

(Byoung Kwon et al. 2001) suggested wall shear stress to be additional risk factors for the development of artery atherosclerosis, also evaluated the hemodynamic characteristics of an atherosclerosis, especially wall shear stress of artery with $(D=0.3 \mathrm{~cm}), 1-40$ dyne $/ \mathrm{cm}^{2}, 0.1-4 P a$.

Several investigators measured wall shear stress in common carotid artery. (Oshinski et al. 1995) and (Oyre et al. 1997) calculated peak wall shear stress of abdominal aorta 40-48 dyne $/ \mathrm{cm}^{2}$. Also (Gnasso et al 1996) and (Oshinski et al. 2006) measured mean wall shear stress in the common carotid artery 7-15 dyne $/ \mathrm{cm}^{2}$.

A stenosis is the narrow of the artery due to development of arteriosclerosis plaques or other types of abnormal tissue development, as the growth projects into the lumen of the artery, blood flow is obstructed. The obstruction may damage the internal cells of the stenosis. Thus, there is coupling between the growth of a stenosis and the flow of blood in the artery, since each affects the other, the symmetric geometry model of stenosis artery with its equation has been reported by (Kapur, 1985).

\section{The Model Devloped}

By assuming the artery to be circularly cylindrical (Fig. 1), the characteristic of blood in stenosed artery and the stenosis to be symmetric about the axis of artery, the flow of blood in human body under axi- symmetric, the blood to be Newtonian 
incompressible and homogenous.

The equation of shear stress is

$$
\tau=-\mu \frac{\partial v}{\partial r}
$$

The equation of velocity is

$$
v=\frac{G r^{2}}{4 \mu}
$$

Where $\tau$ is the shear stress, $\mu$ is the viscosity, $\partial v / \partial r$ is the velocity gradient or rate of deformation (shear rate), $v$ is the velocity, $\mathrm{G}$ is the pressure gradient and $\mathrm{r}$ is the radius of artery. But $\mathrm{r}=\mathrm{r}(\mathrm{z})$ in the stenosis and $r=R_{0}$ when there is no stenosis then

$$
r(z)= \begin{cases}\left(1-\frac{\delta}{2 R_{0}}\left(1+\cos \pi \frac{z}{z_{0}}\right)\right) & -z_{0}<z<z_{0} \\ 1 & 2 z_{0}<z<-z_{0}\end{cases}
$$

From equation (2) and (3) we get

$$
v=\frac{G}{4 \mu}\left(r^{2}(z)-R_{0}^{2}\right)
$$

Derivative(4), then

$$
\left(\frac{\partial v}{\partial r}\right)_{r=r(z)}=\frac{\partial v}{\partial r} \frac{\partial r}{\partial z}=\frac{G}{2 \mu} r(z) d z
$$

from equations(1) (3)and (5) we get

$$
\tau=-\frac{G}{2}\left[\int_{-z_{0}}^{z_{0}}\left(1-\frac{\delta}{2 R_{0}}\left(1+\cos \pi \frac{z}{z_{0}}\right)\right) d z+\int_{2 z_{0}}^{-z_{0}} d z\right]
$$

By integrating(6) we get

$$
\tau=\frac{G}{2} z_{0}\left(1+\frac{\delta}{R_{0}}\right)
$$

\section{Boundary Conditions}

1) $\tau \rightarrow \infty$ at $R_{0}=0$

2) When $\delta=0, \tau=\frac{G}{2} z_{0}$, this mean that $z_{0}=R_{0}$

\section{Results Conclusion}

The results based on the numerical solution of equation (7) by using a mathematical software for $2 z_{0}=R_{0}, 2 z_{0}=2 R_{0}$ and $2 z_{0}=3 R_{0}$ for height stenosis $(0.05$ to $0.1 \mathrm{~cm})$ indicate that, wall shear stress increases with the increase of height stenosis and while pressure gradient so, wall shear stress also increases with the increase of length stenosis, so other parameters are constant. It is clear that if $R_{0}=0$ wall shear stress is out of order.

The results listed in (Tables 1-3) and curves (Fig.2-3) show that, a range of wall shear stress is 0.4 to 4.5 pa, while a range of pressure gradient is 500 to $2000 \mathrm{pa} / \mathrm{m}$.

\section{References}

Byoung kwon lee \& et al. (2002). Hemodynamic effects on atherosclerosis-prone coronary artery: wall shear stress / rate distribution and impedance phase angle in coronary and aortic circulation.Yonsei medical journal, vol.42, 375-383.

Chan. W. Y, Ding. Y \& Tu. G. Y (2007). Modeling of non-Newtonian blood flow through a stenosis artery incorporating fluid-structure interaction. Anziam J., 47. 507-523, [Online] Available: http://anziamj.austms.org.au/ojs/index.php/ANZIA MJ/article/viewFile/1059/1001.

Gnasso A, Carallo C, Irace C \& et al. (1996). Association between intima-media thickness and wall shear stress in common carotid arteries in healthy male subjects. Circulation, 94:3257 -3262. 
Gringioni. M \& Pontrelli. G. (2002). The role of wall shear stress in unsteady vascular dynamics, vol. 7, $204-212$. [Online] available: http://www.iac.rm.cnr.it/ pontrell/pub/finalbruse.pdf.

Kaazempur-Mofrad. M. R, Wada. S, Myers. J, G \& Ethier. C. R. (2005). Mass transport and fluid flow in stenosis arteries: Axisymmetric and asymmetric models. International journal of health and mass transfer, 48. 907-918. [Online] Available: http://biomechanics.berkeley.edu/assets/papers/Stenosis.pdf.

Kapur, J. N. (1985). Mathematical Models in Biology and Medicine. Affiliated East-West Press Pvt. Ltd., New Delhi. Chapter 11.

Liu .G. T, Wang. X. J, Ai. B. Q \& Liu. L. G. (2004), Numerical study of pulsating flow through tapered artery with stenosis. Chinese Journal of Physics, vol. 42. 401- 409.

Nerem. R. (1992). Vascular fluid mechanics the arterial wall and atherosclerosis. Biology J., 114,274-282.

Oshinski JN, Ku DN, Mukundan S Jr, Loth F, Pettigrew RI. (1995). Determination of wall shear stress in the aorta with the use of MR phase velocity mapping. J. Magn Reson Imaging, 5:640-647.

Oshinski JN, Curtin JL \& Loth F. (2006). mean -average wall shear stress measurement in the common carotid artery. $J$ cardivasc Magn Reson, 8:717-722.

Oyre S, Pedersen EM, Ringgaard S, Boesiger P \& Paaske WP. (1997). In vivo wall shear stress measured by magnetic resonance velocity mapping in the normal human abdominal aorta. Eur J Vasc Endovasc Surg, 13:263 -271.

Table 1. Data on wall shear stress for different values of pressure gradient and lengths of stenosis, with height stenosis is $\delta=0.001 \mathrm{~m}$ and $R_{0}=0.002 \mathrm{~m}$

\begin{tabular}{cccc}
\hline $\begin{array}{c}\text { Pressure } \\
\text { Gradient }\end{array}$ & $\begin{array}{c}\text { WSS (pa) } \\
\text { at } 2 z_{0}=R_{0}\end{array}$ & $\begin{array}{c}\text { WSS (pa) } \\
\text { at } 2 z_{0}=2 R_{0}\end{array}$ & $\begin{array}{c}\text { WSS (pa) } \\
\text { at } 2 z_{0}=3 R_{0}\end{array}$ \\
\hline 500.000 & 0.312500 & 0.562500 & 0.937500 \\
666.666 & 0.425926 & 0.766667 & 1.277778 \\
833.333 & 0.543981 & 0.979167 & 1.631944 \\
1000.00 & 0.666667 & 1.200000 & 2.000000 \\
1166.66 & 0.793981 & 1.429167 & 2.381944 \\
1333.33 & 0.925926 & 1.666667 & 2.777778 \\
1500.00 & 1.062500 & 1.912500 & 3.187500 \\
1666.66 & 1.203704 & 2.166667 & 3.611111 \\
1833.33 & 1.349537 & 2.429167 & 4.048611 \\
2000.00 & 1.500000 & 2.700000 & 4.500000 \\
\hline
\end{tabular}

Table 2. Data on wall shear stress for different heights and different leigths of stenosis, pressure gradient is $2000 \mathrm{pa} / \mathrm{m}$ and $R_{0}=0.002 \mathrm{~m}$

\begin{tabular}{cccc}
\hline $\begin{array}{c}\text { height of stenosis } \\
\left(\times 10^{-} 4\right) m\end{array}$ & $\begin{array}{c}\text { WSS (pa) } \\
\text { at } 2 z_{0}=R_{0}\end{array}$ & $\begin{array}{c}\text { WSS (pa) } \\
\text { at } 2 z_{0}=2 R_{0}\end{array}$ & $\begin{array}{c}\text { WSS }(\mathrm{pa}) \\
\text { at } 2 z_{0}=3 R_{0}\end{array}$ \\
\hline 5.000000 & 1.250000 & 2.25 & 3.750000 \\
5.555556 & 1.277778 & 2.30 & 3.833333 \\
6.111111 & 1.305556 & 2.35 & 3.916667 \\
6.666667 & 1.333333 & 2.40 & 4.000000 \\
7.222222 & 1.361111 & 2.45 & 4.083333 \\
7.777777 & 1.388889 & 2.50 & 4.166667 \\
8.333333 & 1.416667 & 2.55 & 4.250000 \\
8.888889 & 1.444444 & 2.60 & 4.333333 \\
9.444444 & 1.472222 & 2.65 & 4.416667 \\
10.00000 & 1.500000 & 2.70 & 4.500000 \\
\hline
\end{tabular}


Table 3. Data on wall shear stress for different lenghts of stenosis, pressure gradient is $2000 \mathrm{pa} / \mathrm{m}$, height of stenosis $\delta=0.001 \mathrm{~m}$ and $R_{0}=0.002 \mathrm{~m}$

\begin{tabular}{cc}
\hline $\begin{array}{c}\text { leingth of } \\
\text { stenosis } \mathrm{m}\end{array}$ & $\begin{array}{c}\text { Wall shear stress } \\
(\mathrm{Pa})\end{array}$ \\
\hline 0.002000 & 1.500000 \\
0.002444 & 1.833333 \\
0.002889 & 2.166667 \\
0.003333 & 2.500000 \\
0.003778 & 2.833333 \\
0.004222 & 3.166667 \\
0.004667 & 3.500000 \\
0.005111 & 3.833333 \\
0.005556 & 4.166667 \\
0.006000 & 4.500000 \\
\hline
\end{tabular}

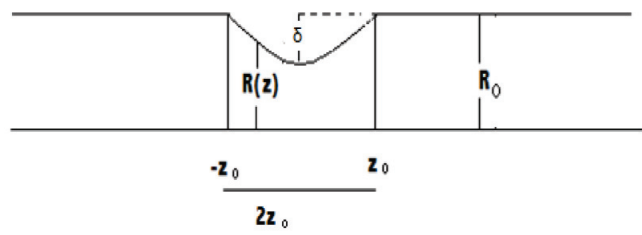

Figure 1. Physical Model and Coordinates System

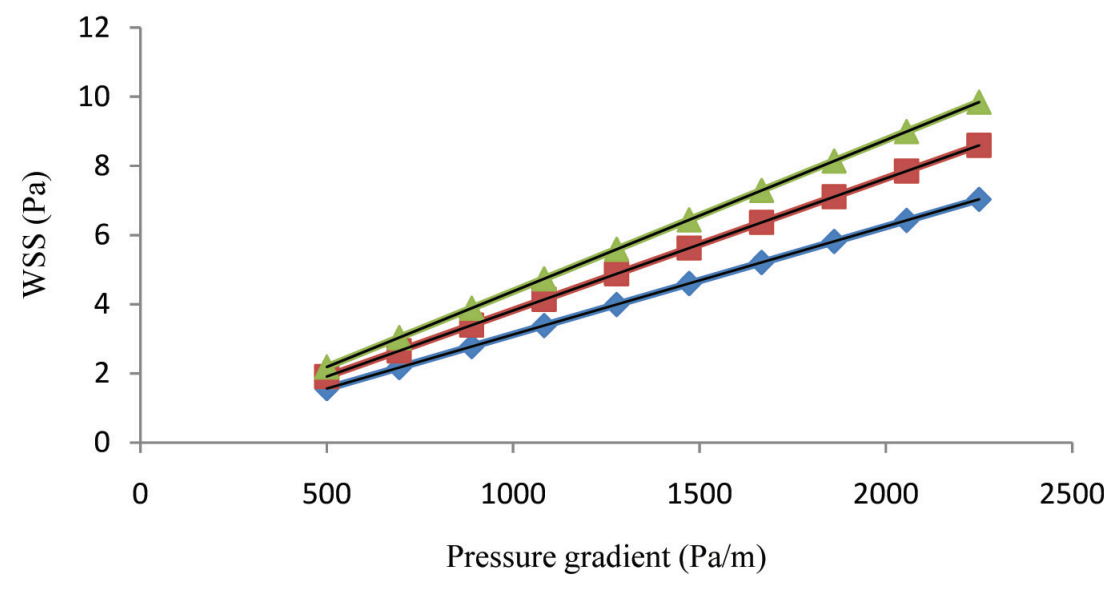

$\neg 1-2 \rightarrow-3$

Figure 2. Effect of Pressure gradient on wall shear stress, with different ratio $\delta / R_{0}$ $\left(1-\delta / R_{0}=0.25\right)\left(2-\delta / R_{0}=0.52\right)$ and $\left(3-\delta / R_{0}=0.75\right)$, length of stenosis is $0.01 \mathrm{~m}$ 


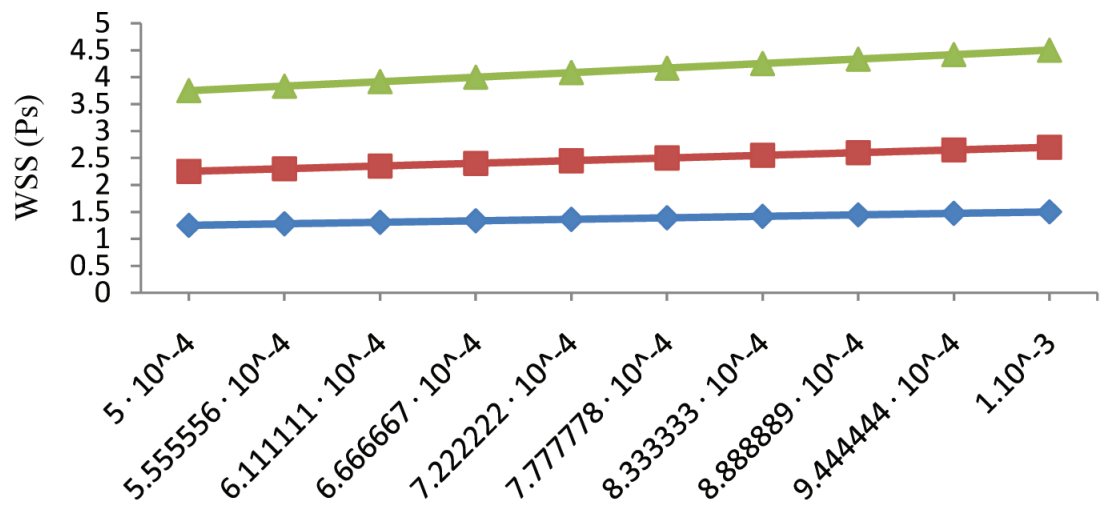

Hieght of stenosis(m)

$-1-2 \rightarrow-3$

Figure 3. Effect of height stenosis ( $\delta$ ) on wall shear stress, with different lengths of stenosis

(1) $2 z_{0}=R_{0}(2) 2 z_{0}=2 R_{0}$ and (3) $2 z_{0}=3 R_{0}$ 